\title{
Design of Water Heater Control System Based on GPRS Technology
}

\author{
Jie Huang \\ College of Information and Communication Engineering, Hezhou University, Hezhou, China, \\ 542899 \\ huangjie0773@163.com
}

Keywords: GPRS; Water heater; Control system; S3C44B0X; Temperature sensor

\begin{abstract}
Aiming at the problems and shortcomings of the water heater control system, based on the actual demand of the water heater control system, a water heater control system was studied and designed by using GPRS technology. The hardware design, software design and the working principle of the system are described in this paper. The system has been tested. The test results show that it has the advantages of good stability, high performance price ratio and convenient operation. The function and performance of the system meet the design requirements. It has great application value.
\end{abstract}

\section{Introduction}

With the development of society, the water heater has been more and more widely used. It provides great convenience to our life $[1,2]$. Generally, the water heater control system does not have the function of variable volume hot water. User can't set the water heater capacity value. The volume of the water heater is fixed. If the volume of the water heater is relatively large, the user uses less hot water. It is easy to cause waste of hot water [3,4]. On the one hand, the water heater control system usually has an appointment hot water function. If the user sets the time for the appointment of hot water, but for some reason the user can not go home to use hot water. Because the user can not cancel the appointment, the system will still be water heating and insulation. It is easy to cause waste of hot water. On the other hand, the water heater control system usually does not have remote control function. When it is used, the user is not convenient $[5,6]$. In this paper, a water heater control system is researched and designed based on GPRS technology. It not only has the function of variable volume hot water, but also has the function of remote control.

\section{System Principle and Hardware Design}

System Structure. The system uses S3C44B0X microprocessor as the core control chip. The system hardware module is composed of temperature sensor module, water level sensor module, heating module, GPRS module, display module and sound and light alarm module. The system structure is shown in Fig. 1. According to the actual needs of the water heater, several temperature sensor modules, several water level sensor modules and several heating modules can be arranged in the system.

System Principle. The water level sensor is used to detect the water level in the water heater $[7,8]$. It is connected with the S3C44B0X microprocessor through the I/O port of the S3C44B0X microprocessor. The water level sensor is used to measure the residual water capacity of the water heater. According to the actual needs of the water heater, several water level sensors can be installed in the system.

The keyboard is connected with the S3C44B0X microprocessor through the I/O port of the S3C44B0X microprocessor. On the one hand, the user can set the temperature of the water heater through the keyboard. On the other hand, the user can also set the appointment of the water heater heating time, heating mode and the water heater capacity through the keyboard.

Memory is used to store program code and data. For example, the system can store the preset heating time of the water heater, the heating mode of the water heater and the water temperature of the water heater through the memory. 


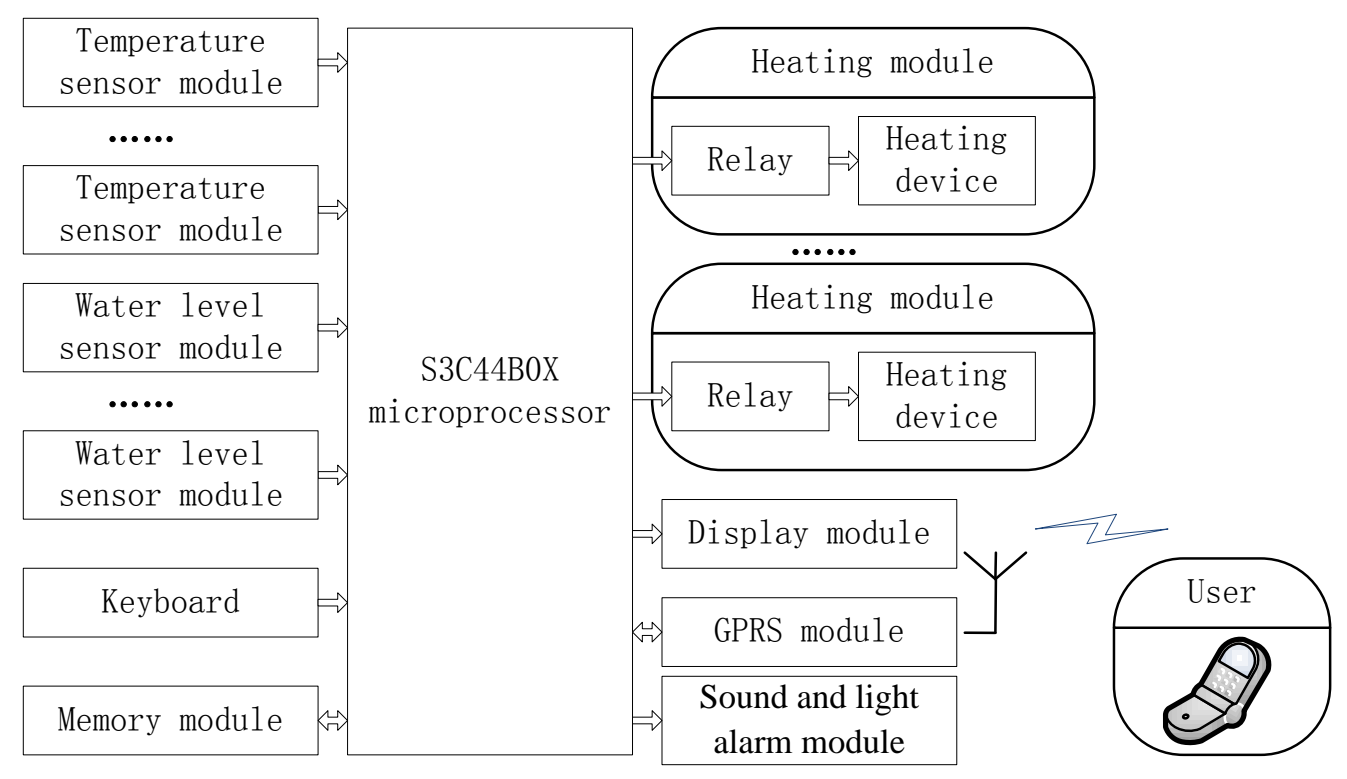

Figure 1. System structure

The heating module is used to heat the water in the water heater. It includes relays and heating devices. The relay is connected with the S3C44B0X microprocessor through the I/O port of the S3C44B0X microprocessor. The opening and closing of the power supply in the heating device is controlled by the relay. According to the actual needs of the water heater, a plurality of heating modules can be installed in the system. The user can select the heating mode of the water heater through the keyboard. For example, user can select a single heating module to heat the water through the keyboard. It can also select a plurality of heating modules to heat the water in the water heater. When a heating module fails, the system can also choose other heating modules to heat the water. It effectively improves the stability of the system.

The GPRS module is connected with the S3C44B0X microprocessor through the serial port $[9,10]$. The system communicates with the user's mobile phone through the GPRS network. Users can use the phone to remotely control the water heater. At the same time, users can also use the phone to query the system operating state and water temperature value. If the user can not go home to use hot water, it can send the control information to the system through the mobile phone to cancel the appointment and disconnect the power supply of the water heater.

The display module is composed of a LCD liquid crystal display and a light emitting diode. It connects to the S3C44B0X microprocessor through the I/O port of the S3C44B0X microprocessor. It is used to display the status information of the water heater control system. For example, the system can display the current temperature of the water heater and the remaining hot water capacity through the LCD display. The light emitting diode is used to display the working state of the power supply of the system. When the user enters data through the keyboard, the display module also provides the user with a friendly human computer interaction interface.

The sound and light alarm module is composed of a buzzer, a light emitting diode and other peripheral circuits. Sound and light alarm module is connected with the S3C44B0X microprocessor through the I/O port of the S3C44B0X microprocessor. When the system has a special situation, the system can send out sound and light alarm signal through the sound and light alarm module to remind the user that the water heater control system has a special situation. For example, when the capacity of the remaining water in the water heater is insufficient, the system can send out an alarm signal through the sound and light alarm module. Users can take timely measures according to alarm information.

Hardware Circuit Design of Temperature Sensor Module. The temperature sensor is used to detect the water temperature in the water heater. According to the actual needs of the water heater, it can include a plurality of temperature sensors, which are installed in the appropriate place in the water heater. The system uses the temperature sensor to detect the water temperature in the water 
heater. When the water temperature reaches the user's set value, the system carries on the insulation to the water. The hardware circuit of the temperature sensor is shown in Fig. 2.

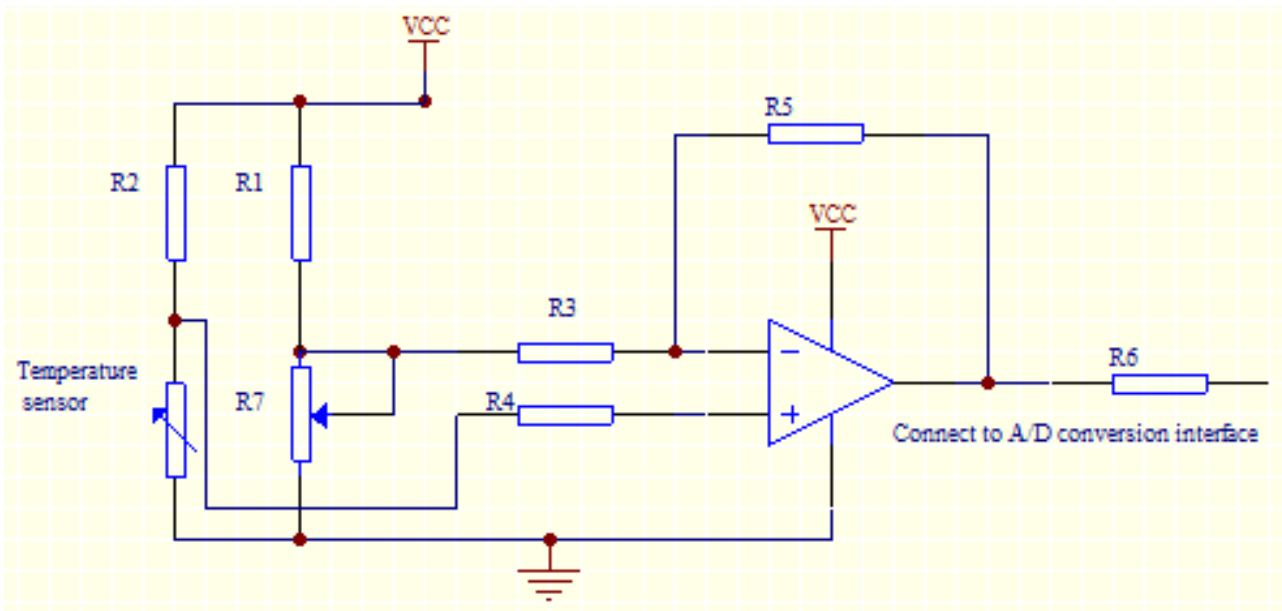

Figure 2. Hardware circuit of temperature sensor

\section{System Software Design}

Functional Design of the System. The main functions of the system are as follows.

1) It has the function of variable volume hot water. According to the actual demand for hot water, the user can set the water heater capacity through the keyboard. On the one hand, it not only meets the needs of users for hot water, it can effectively avoid the waste of hot water. On the other hand, it can save power consumption effectively.

2) It has remote monitoring function. The system can communicate and transmit information to the user's mobile phone through GPRS network. On the one hand, user can use the phone to remotely control the system. On the other hand, user can also use mobile phones to query the working state of the system.

3) It has two working modes. According to the actual needs, user can choose the working mode of the system flexibly. When the system works in mode 1 , according to the set water capacity value, cold water is injected into the water heater. Water is heated and insulated by heating module. In the process of using hot water, cold water is not injected into the water heater. When the system works in mode 2, cold water is filled with water heater. Water is heated and insulated by heating module. In the process of using hot water, if the capacity of the remaining hot water in the water heater is lower than the threshold value set by the system, the system automatically injects cold water into the water heater. The water in the water heater is heated rapidly to meet the needs of users for hot water.

4) It has alarm function. For example, when the remaining hot water in the water heater is not enough, it sends out alarm signal. According to the alarm information, user can take timely measures.

5) It has a variety of heating methods. The water heater is provided with a plurality of heating modules. According to the actual needs, the user can choose the heating mode of the water heater. The user can select a single heating module to heat water, and it can also select a plurality of heating modules to heat water.

Algorithm for Measuring Water Temperature. An important performance index of water heater is to measure the water temperature accurately. A plurality of temperature sensors are respectively arranged at different positions in the water heater. Because of the uneven distribution of water temperature in the heater, in order to accurately measure the water temperature, the following water temperature measurement algorithm is used to measure the water temperature.

1) The temperature of the water heater is measured by the temperature sensor. Water temperature value is saved by system. 
2) It is assumed that $n$ temperature sensors are installed in the water heater. Each temperature sensor has a unique number. It is assumed that $H_{23}$ is the three data collected by the temperature sensor, and the number of the temperature sensors is two.

3) According to the Eq.1, the average value of water temperature is calculated after several measurements.

$$
H_{i}=\frac{1}{z} \sum_{j=1}^{z} H_{i j}(i=1,2, \ldots, n ; z=1,2,3 \ldots)
$$

4) According to the Eq.2 and Eq.3, the temperature value of each temperature sensor is weighted sum. The value of $\alpha_{i}$ can be set according to the capacity of the water heater and the installation position of the temperature sensor.

$$
\begin{aligned}
& H=\sum_{i=1}^{n} \alpha_{i} H_{i} \\
& 1=\sum_{i=1}^{n} \alpha_{i}
\end{aligned}
$$

Flow Chart of the Main Program of the System. According to the actual demand of hot water, user can set the working mode, heating mode, water temperature value and appointment hot water time of the water heater control system through the keyboard or the mobile phone. When the user goes out, the system can be remotely monitored by the user through the phone. The user can view the current water temperature of the water heater, the capacity value of the remaining hot water, heating mode and the working mode of the system through the display module. The main program flow chart of the system is shown in Fig. 3.

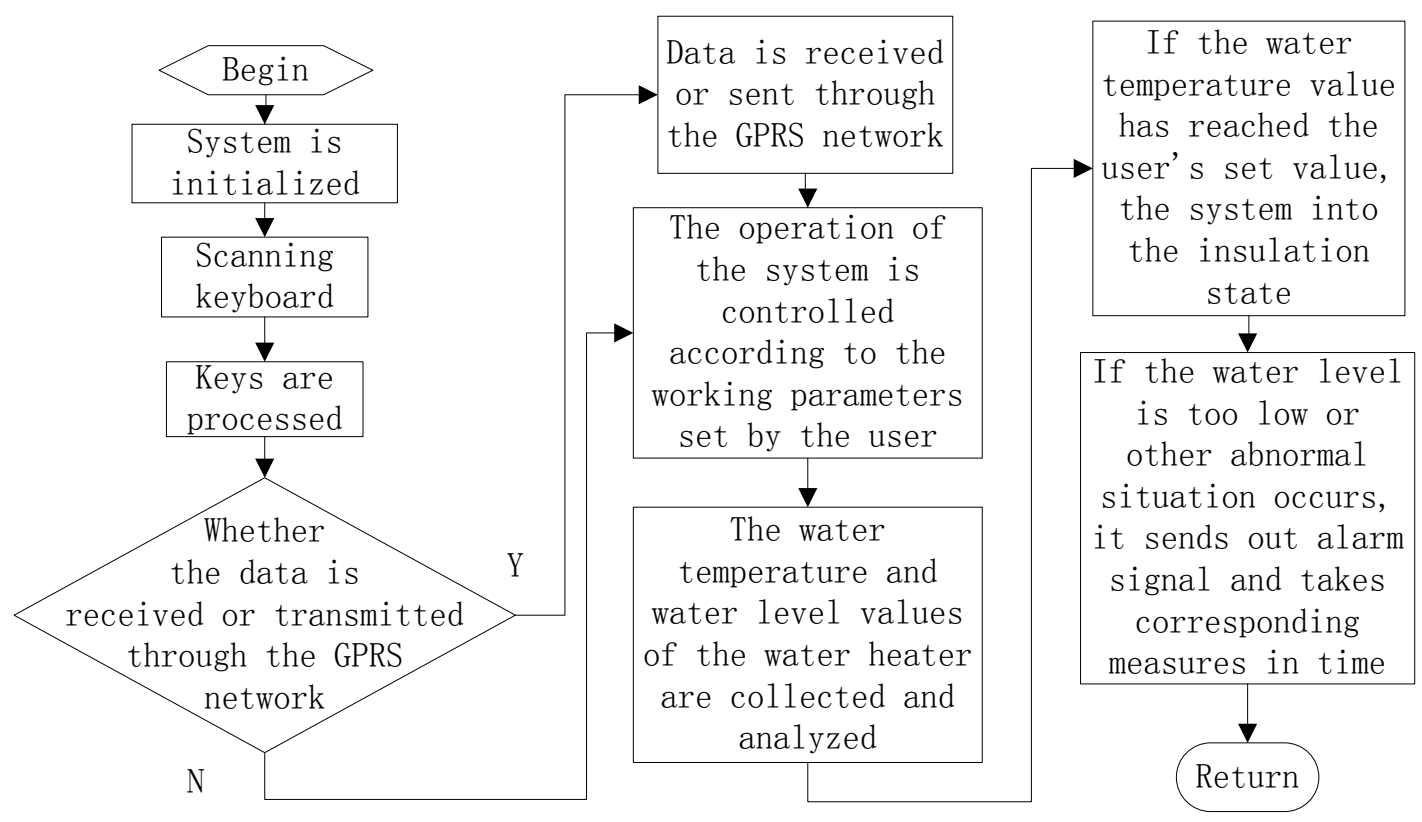

Figure 3. The main program flow chart of the system

\section{System Test}

In order to test the function and performance index of the system, it is installed on a water heater. The functions and indexes of the system are tested. The test results are shown in Table 1 . The test results show that the functions and indicators meet the design requirements and control requirements of the system. 
Table 1 System test data

\begin{tabular}{ccc}
\hline Test item & Test content & Success rate \\
\hline Variable volume hot water function & Change the water heater capacity & $100 \%$ \\
& Remote control test & $100 \%$ \\
Remote monitoring function & Remote monitor test & $100 \%$ \\
& Heating by a single heating module & $100 \%$ \\
Heating mode & Heating by multiple heating modules & $100 \%$ \\
& A low water level & $100 \%$ \\
Alarm function & Other abnormal conditions & $100 \%$ \\
& The system operates in mode 1 & $100 \%$ \\
Working mode & The system operates in mode 2 & $100 \%$ \\
\hline
\end{tabular}

\section{Conclusions}

A water heater control system is researched and designed based on GPRS technology. It can remotely control the opening and closing of the water heater, the hot water time, the working mode and the heating mode through the mobile phone and the GPRS network. It has variable volume hot water function. According to the actual demand of the hot water, user can flexibly set the hot water capacity of the water heater. The system can not only save energy effectively, but also avoid wasting water. It has two working modes and various heating modes. According to the actual needs, user can flexibly select and set the system working mode and heating mode. The system has the advantages of flexible control, good stability and convenient operation. It has great application value.

\section{Acknowledgement}

This work was financially supported by the National Natural Science Foundation of China (Grant No. 6154055).

\section{References}

[1] Z.Q. Tang, J.J. Yang, Z.B. Lou and C.J. Wei: Instrumentation Technology, Vol. 23 (2016) No.3, p.1. (In Chinese)

[2] X.D. Hao: Journal of Shanxi Normal University(Natural Science Edition), Vol. 30 (2016) No.1, p.53. (In Chinese)

[3] C.L. Du: ARM architecture's stuction and programme (Tsinghua University Press, Chinese 2003), p.65. (In Chinese)

[4] B.J. Zhou and P. Jiang: Modern Electronics Technique, Vol. 38 (2015) No.22, p.73. (In Chinese)

[5] S.P. Mo: Value Engineering, Vol. 32 (2013) No.23, p.49. (In Chinese)

[6] C. Xia and W.Q. Ling: Microcomputer \& Its Applications, Vol. 33 (2014) No.19, p.94. (In Chinese)

[7] L.L. Wang and J.P. Zhao: Electronic Technology, Vol. 47 (2014) No.10, p.52. (In Chinese)

[8] S. Liang, J.Q. Dai and Z.H. Feng: Industrial Control Computer, Vol. 29 (2016) No.2, p.40. (In Chinese)

[9] H.D. Zhu: Science and Technology \& Innovation, Vol. 3 (2016) No.12, p.111. (In Chinese)

[10] S.B. Tong and C.Y. Hua: Fundamentals of Analog Electronic Technology (Higher Education Press, Chinese 2006), p.125. (In Chinese) 